\title{
Intraspecific Genome Size Variation in Pumpkin (Cucurbita pepo subsp. pepo)
}

\author{
A. Lane Rayburn ${ }^{1}$ \\ Department of Crop Sciences, University of Illinois at Urbana-Champaign, \\ 1201 West Gregory Drive, Urbana, IL 61801
}

Mosbah M. Kushad and Wanisari Wannarat

Department of Natural Resources and Environmental Sciences, University of Illinois at Urbana-Champaign, 1201 West Gregory Drive, Urbana, IL 61801

Additional index words. pie pumpkin, flow cytometry, genome size

\begin{abstract}
Genome size has recently been reported to vary $16 \%$ in pumpkins (Cucurbita spp.). The majority of this variation can be attributed to genome size differences in pumpkins of various taxonomical classes. The purpose of this study was to determine if intraspecific genome size variability could be detected by flow cytometry in Cucurbita pepo subsp. pepo pumpkin cultivars with similar fruit morphology. The pie pumpkins group was chosen for this study because of their similar fruit size, shape, and color. Genome sizes ranged from $1.109 \mathrm{pg}$ in Spooktacular to $1.064 \mathrm{pg}$ in Small Sugar. Spooktacular had a genome size larger than Small Sugar in all three experiments. Therefore, intraspecific genome size variation does exist in $C$. pepo subsp. pepo among pumpkin cultivars of similar fruit morphology.
\end{abstract}

Changes in cellular parameters that are brought about by variations in genome size are referred to as nucleotypic effects (Bennett, 1972; Rayburn, 1993a). Nucleotypic effects have been observed in various plant species (Bennett, 1976; Chung et al., 1998; Rayburn et al., 1985). A recent study by Tatum et al. (2006) suggested that nucleotypic selection was occurring in pumpkins. In particular, the hypothesis was that genome size (the amount of DNA within the nucleus of a cell) fluctuated and that this fluctuation influenced cell size in pumpkins and thus ultimately influenced fruit size. One caveat to nucleotypic studies is to ensure that true genome size variation exists within the species in question.

Over the past several years, concerns have been raised over the methods used to determine intraspecific genome size variation (Greilhuber, 2005). These concerns have led to doubts of the existence of intraspecific genome size variation and the amount of such variation. With the exception of maize (Zea mays; Rayburn et al., 1985; Rayburn et al., 1989), most reports of high genome size variation have not stood up under closer scrutiny (Greilhuber, 2005). For instance, soybean (Glycine max) has a reported genome size variation range between $40 \%$ and $0 \%$, with two independent studies now agreeing on about a $4 \%$ variation (Chung et al., 1998; Rayburn et al., 2004). Several studies have documented a small genome

Received for publication 21 Aug. 2007. Accepted for publication 27 Nov. 2007.

We thank Dr. B. Pilas of the Flow Cytometry Facility, a resource of the University of Illinois Biotechnology Center, for her assistance.

${ }^{1}$ To whom reprint requests should be addressed; e-mail arayburn@uiuc.edu size variation within plant species, with one report documenting about a $1 \%$ variation between different wheat cultivars (Wetzel et al., 1999). This small variation was supported by the cytological data of Wetzel and Rayburn (2000).

Pumpkin is a somewhat arbitrary term usually referring to "any squash used for pies, jack-o'lanterns, or stock feed" (Robinson and Decker-Walters, 1997). Pumpkin encompasses various Cucurbita L. species such as Cucurbita pepo L., C. maxima Duchesne, C. moschata Duchesne, and C. argyrosperma C. Huber.

The pumpkins studied by Tatum et al. (2006) were of two species, C. pepo and $C$. maxima. The reported fruit weight of these pumpkins ranged from 0.11 to $273 \mathrm{~kg}$ (Anonymous, 2005). Tatum et al. (2006) observed up to a $16 \%$ variation in genome size in pumpkins, with the smallest genome sizes found in two pumpkin fruit types: miniature and jumbo. These two fruit types represent the extreme diversity found in pumpkin with regard to fruit size. The jumbo pumpkin cultivars are of the species C. maxima and produce fruits ranging from 22.7 to $273 \mathrm{~kg}$ (University of Illinois Extension, 2005a). Although it is interesting that the C. maxima cultivars have a smaller genome size than most of the $C$. pepo cultivars, this fact sheds no light on existence of intraspecific variation because any differences observed would represent interspecific variation. The miniature fruit types, i.e., Jack-B-Little, that Tatum et al. (2006) also found to have small genome sizes have the smallest fruit type of the pumpkins. Plant and fruit size have been hypothesized to correlate with altered genome sizes in plant species (Rayburn et al., 1985; Tatum et al., 2006). Therefore, although the $13 \%$ to $16 \%$ variation observed by Tatum et al. (2006) may indeed be intraspecific variation, it could be from the extreme fruit size difference among these pumpkins. An additional problem with the inclusion of Jack-B-Little types in intraspecific genome size variation studies in pumpkin is the possibility that these miniature pumpkin types may actually represent another taxonomic class in $C$. pepo.

Goldman (2004) indicates that Jack-BLittle is not actually a pumpkin but is instead an acorn squash. If Jack-B-Little types are acorn squash, they would be of the subspecies "texana" not "pepo" (Paris et al., 2003). If one truly wants to focus on intraspecific variation, only plants of $C$. pepo subsp. pepo should be compared. When the miniature pumpkins were removed from the analysis of Tatum et al. (2006), the amount of intraspecific genome size variation, although reduced to $\approx 4 \%$, was still statistically significant. However, even this small variation included pumpkins of vastly different fruit size. Gasmanova et al. (2007) also noted genome size variation in widely variable $C$. pepo accessions. The question becomes: Can genome size variation occur in pumpkins of similar morphology?

The purpose of this study was to document genome size variation in C. pepo subsp. pepo pumpkins of similar fruit morphology. The experiment was replicated over time, and statistical analyses were performed to ensure only true genome size variation was reported.

\section{Materials and Methods}

Pumpkins tested were of the subspecies $C$. pepo subsp. pepo with the exception of JackB-Quik, which is C. pepo subsp. ovifera (L.) D.S. Decker var texana (Scheele) Filov. The seeds were obtained from Rupp Seed, Inc. (Wauseon, $\mathrm{OH}$ ). The first 10 cultivars listed in Table 1 of are of similar fruit morphology and are referred to as pie pumpkins based on their sweet, less watery flesh (University of Illinois Extension, 2005b). Little October and Jack-B-Quik, classified as miniature pumpkins (Rupp Seed, Inc. catalog), were selected for their high and low genome sizes, respectively (Tatum et al., 2006).

Plants were grown in the laboratory in Hummert Growing Mix No. 2 Lightweight Mix. One Sylvania Gro-Lux 40w light bulb and one Cool White Deluxe 40w light bulb were used for the light source with an irradiance level of $83 \mathrm{mmole} \cdot \mathrm{m}^{-2} \cdot \mathrm{sec}^{-1}$ photosynthetically active radiation (400-800 $\mathrm{nm})$. The lights were set on a 16-h light/8-h dark cycle.

The nuclei were isolated according to Rayburn et al. (1989). Briefly, a 2-cm segment of pumpkin leaf tissue from each plant and a rolled leaf portion above the growing point of the maize seedling were cochopped and placed in a beaker containing $10 \mathrm{~mL}$ of extraction buffer and $200 \mu \mathrm{L}$ of $25 \%$ Triton $\mathrm{X}$. The material was then homogenized with a tissue grinder for $10 \mathrm{~s}$, and then the homogenate was filtered through a $250-\mu \mathrm{m}$ and a $53-$ $\mu \mathrm{m}$ diameter nylon mesh filter. The samples 
Table 1 . The $2 \mathrm{C}$ genome size of the pumpkin cultivars.

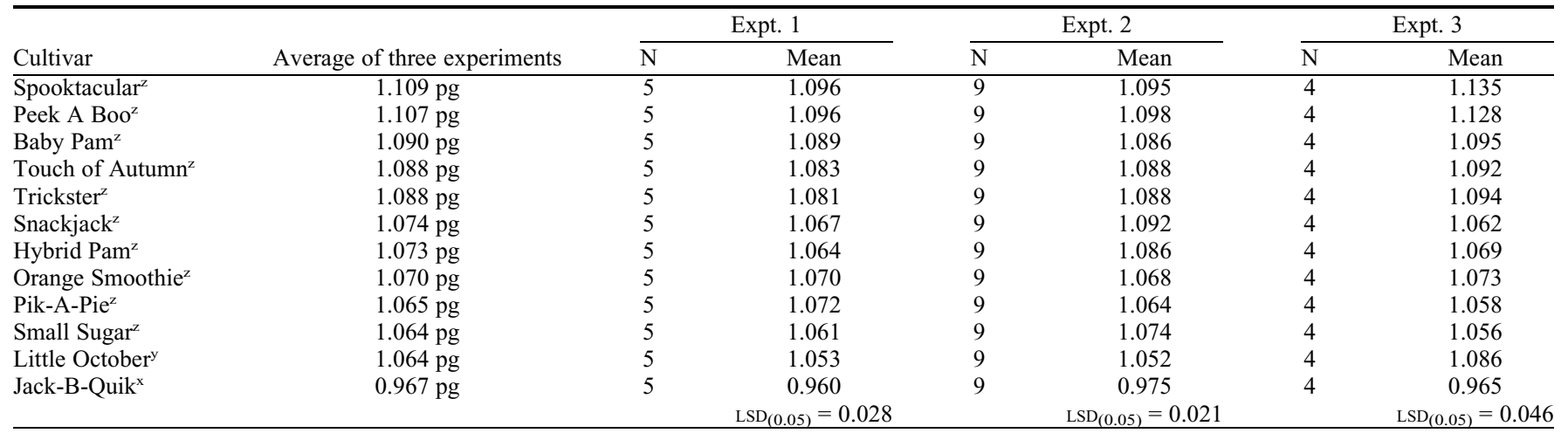

${ }^{\text {zPie pumpkins, C. pepo var. pepo. }}$

${ }^{\mathrm{y}}$ Miniature pumpkin, $C$. pepo var. pepo.

${ }^{\mathrm{x}}$ Miniature pumpkin, C. pepo var. texana.

were centrifuged at $200 g_{n}$ for $15 \mathrm{~min}$ at $4{ }^{\circ} \mathrm{C}$, the supernatant was aspirated, and the pellet was resuspended in $300 \mu \mathrm{L}$ of propidium iodide stain (Bashir et al., 1993). Samples were then placed in a $37^{\circ} \mathrm{C}$ water bath for $20 \mathrm{~min}$. Afterward, $300 \mu \mathrm{l}$ of propidium iodide salt (Bashir et al., 1993) was added to each sample and samples were vortexed for $\approx 2 \mathrm{~s}$. The samples were placed on ice, covered, and stored at $4{ }^{\circ} \mathrm{C}$ for at least $1 \mathrm{~h}$.

Samples were analyzed using a Flow Cytometer-Cell Sorter Epics XL-MCL (Coulter Electronics, Hialeah, FL) set at a $488 \mathrm{~m}$ laser wavelength. A histogram plotting the frequency of nuclei versus the fluorescence channel was produced. The relative fluorescence between the pumpkin G1 peak and the maize G1 peak was used to convert fluorescence intensity to picograms of DNA.

The experiment was repeated three times over a 7-month period. A total of five, nine, and four replicates per cultivar were analyzed in the first, second, and third experiments, respectively. Each replication consisted of a single plant, which was analyzed on a separate day. For each replicate, one small leaf of pumpkin and a small leaf segment of the maize line W22 were chopped together. Cochopping with the maize line W22 provided an internal standard. The reason this maize line was selected is that it has consistently been reported to have 5.35 pg per $2 \mathrm{C}$ nucleus (Rayburn et al., 2005). For consistency, the nuclear DNA amount is reported as pg per 2C nucleus, the amount of DNA per diploid G1 nucleus (Rayburn, 1993b). The experimental design was a completely randomized block with blocks being days. Statistical analysis of the DNA contents was performed using SAS (version 8.2, SAS Institute, Cary, NC), PROC GLM.

\section{Results and Discussion}

Little October was observed to have an average genome size of $1.064 \mathrm{pg}$, whereas Jack-B-Quik was observed to have 0.967 pg (Table 1). These results confirm the results from our previous study (Tatum et al., 2006) in which we reported the genome size of Little October to be $1.06 \mathrm{pg}$ and the genome size of
Jack-B-Quik to be $1.00 \mathrm{pg}$. These results are also consistent with those of Gasmanova et al. (2007), which found cultivars of $C$. pepo subsp. texana to have lower DNA amounts than $C$. pepo subsp. pepo. The genome size of the Little October in this study was very similar to that observed by Tatum et al. (2006). The similarity of genome sizes between the two studies further validates the consistency of genome size determination of pumpkins cultivars by flow cytometry.

The genome size of Little October was smaller than most of the pie pumpkins (Table 1). Little October was selected based on our previous observation that this cultivar had a medium to large genome size compared with other pumpkins (Tatum et al., 2006). The fact that none of the pie pumpkins in this study had a genome size smaller than Little October was unexpected. The genome sizes of the pie pumpkins were larger than expected and exceeded the DNA range of the controls.

With respect to the three experiments, the observed genome sizes were similar in eight of the 12 cultivars examined (Table 1). Three of the cultivars (Small Sugar, Hybrid Pam, and Snackjack) had aberrantly larger genome sizes in Exp. 2, whereas Little October had a larger genome size in Exp. 3 (Table 1). Final comparisons among the cultivars were made based on the average of the three experiments.

In all three experiments, Spooktacular and Peek-a-Boo were observed to have the largest genome sizes and had significantly larger genome sizes than Jack-B-Quik and Small Sugar (Table 1). Overall, when comparing the means, the variation in genome size between Spooktacular and Jack-B-Quik was $\approx 15 \%$. This genome size variation is similar to the amount of variation observed by Tatum et al. (2006). Two studies have now confirmed that genome size variation exists in pumpkins and that the variation is $\approx 15 \%$. However, this variation includes the miniature pumpkin cultivar Jack-B-Quik. As such, the amount of variation may be exacerbated by the inclusion of this cultivar that has relatively small fruit size and is of a different subspecies. Because all of the pie pumpkins were C. pepo subsp. pepo and had fruit of similar morphology, drastic differences in fruit type did not complicate the present study.

Baby Pam, Touch of Autumn, and Trickster were observed to rank consistently in the top five genome sizes in all three experiments. Although statistical significance did vary among the three experiments, the rankings of these cultivars were reproducible. Pik-A-Pie and Small Sugar followed a similar pattern, always ranking low with respect to genome size in all three experiments. Thus, the genome size differences are real and reproducible.

When comparing the mean genome sizes of Peek-A-Boo and Small Sugar (the pie pumpkin cultivar with the smallest genome size), overall, a $4 \%$ variation was observed. Although smaller than the $15 \%$ variation observed between Jack-B-Quik and Spooktacular, the genome sizes of Peek-A-Boo and Small Sugar were consistently statistically significant at $\alpha=0.05$. Given the reproducibility of the results, this variation in genome size appears real. The amount of variation observed here in pumpkins is similar to amount of variability seen in soybean and much less than that observed in maize (Rayburn et al., 2004).

Intraspecfic genome size variation has now been confirmed in C. pepo subsp. pepo pumpkin cultivars. This genome size variation is found in one specific group of pumpkins, indicating that genome size variation can occur among pumpkin cultivars of similar morphology. Upon comparing genome size with reported fruit size in these pie pumpkins, a complex relationship between genome size and fruit size seems to be indicated. Further studies are underway to confirm that the observed genome size variation is associated with nucleotypic characteristics such as fruit size.

\section{Literature Cited}

Bashir, A., J.A. Auger, and A.L. Rayburn. 1993. Flow cytometric DNA analysis of wheat-rye addition lines. Cytometry 14:843-847.

Bennett, M.D. 1972. Nuclear DNA content and minimum generation time in herbaceous plants. 
Proc. Roy. Soc. Lond. B. Biol. Sci. 181:109135.

Bennett, M.D. 1976. DNA amount, latitude, and crop plant distribution. Environ. Exp. Bot. 16:93-108.

Chung, J., J.H. Lee, K. Arumuganathan, G.L. Graef, and J.E. Specht. 1998. Relationship between nuclear DNA content and seed and leaf size in soybean. Theor. Appl. Genet. 96:1064-1068.

Gasmanova, N., A. Ledeba, I. Dolezalova, and H.S. Paris. 2007. Variability in nuclear DNA content among and within three cucrubit genera. Acta Hort. 731:83-88.

Goldman, A. 2004. In. The complete squash: A passionate grower's guide to pumpkins, squashes, and gourds. Workman Publishing, Inc., New York.

Greilhuber, J. and J. 2005. Intraspecific variation in genome size in angiosperms: Identifying its existence. Ann. Bot. 95:255-260.

Paris, H.S., N. Yonash, V. Portnoy, N. MoxesDaube, G. Tzuri, and N. Katzir. 2003. Assessment of genetic relationships in Cucurbita pepo (Cucurbita) using DNA markers. Theor. Appl. Genet. 106:971-978.
Rayburn, A.L. 1993a. Flow cytometric assessment of nucleotype variability and its evolutionary implications in plants, p.110-115. In: Classical and molecular cytogenetics analysis. Proceedings of a U.S.-Japan symposium. Kansas Ag. Exp. Stat. Rept. 95-352-D. 21-24 Mar. 1994, Manhattan, KS.

Rayburn, A.L. 1993b. Comparative studies of genome content, p. 206-212. In: Methods in enzymology. Vol. 224. Molecular evolution: Producing the biochemical data. E.A. Zimmer, T.J. White, R.L. Cann, and A.C. Wilson (eds.). Academic Press, Boston.

Rayburn, A.L., J.A. Auger, E.A. Benzinger, and A.G. Hepburn. 1989. Detection of intraspecific DNA content variation in Zea mays L. by flow cytometry. J. Expt. Bot. 40:1179-1183.

Rayburn, A.L., D.P. Biradar, R.L. Nelson, R. McCloskey, and K.M. Yeater. 2004. Documenting intraspecific genome size variation in soybean. Crop Sci. 44:261-264.

Rayburn, A.L., H.J. Price, J.D. Smith, and J.R. Gold. 1985. C-band heterochromatin and DNA content in Zea mays. Amer. J. Bot. 72:1610-1617.

Rayburn, A.L., R. McCloskey, T.C. Tatum, M.R. Jeschke, and P.J. Trannel. 2005. Genome size analysis of weedy Amaranthus species. Crop Sci. 45:2557-2562.

Robinson, R.W. and D.S. Decker-Walters. 1997. In: Cucurbits. Crop production science in horticulture series. Cab International, New York.

Tatum, T.C., L. Nunez, M.M. Kushad, and A.L. Rayburn. 2006. Genome size variation in pumpkin (Cucurtiba sp.). Ann. Appl. Biol. 149:145-151.

University of Illinois Extension. 2005a. Pumpkins and more. 9 Nov. 2005. http://www.urbanext. uiuc.edu/pumpkins/varieties.html

University of Illinois Extension. 2005b. Pumpkins and more. 9 Nov. 2005. http://www.urbanext. uiuc.edu/pumpkins/selection.html

Wetzel, J.B., S. Aref, V.C. Baligar, and A.L. Rayburn. 1999. A lack of nuclear DNA content variability among wheat near isolines differing in aluminum response. Ann. Bot. (Lond.) 83: 725-728.

Wetzel, J.B. and A.L. Rayburn. 2000. Use of fluorescence genomic in situ hybridization (GISH) to detect the presence of alien chromatin in wheat lines differing in nuclear DNA content. Cytometry 41:36-40. 